\title{
SUPERIORITAS LAKI-LAKI DALAM DUNIA SUFI: Tinjauan Budaya Islam dalam Praktek Kepemimpinan Spiritual
}

\author{
A6durrohmat \\ Universitas Islam Negeri Sunan Gunung Djati Bandung. Jalan Raya Cipadung No.105 \\ Ciburu Bandung Jawa Barat. Telp.(022) 7800525 e-mail: abdurohmat@yahoo.com
}

\section{Abstract}

Substantially, the spiritual teaching of Sufism is not represented and represents one of gender group, male or female an sich. The Sufism spiritual teaching has great universal scope for male and female. In the empirical domain, in fact, the spiritual teaching still conduct patrimonial culture behavior which makes the original Sufism spiritual teaching endangered to fail. This situation also happened in the leadership on the practices of tasawuf teaching culture which has been dominated by the males. As a consequence, the female will never get the chance to lead the teaching practice. The situation encourages the writer to dig up the issues on imbalance in the male and female role in the Sufism teaching practices. The article raises the questions on should the spiritual teacher be the male? And why does the leadership capacity of the spiritual teaching has been dominated by the male? Furthermore, the exploration will be helpful resource to have better understanding on the Sufism teaching practice.

Key words: Islamic culture, spirituality, female and male superiority. 


\section{Pendahuluan}

Mursyid adalah seseorang yang dipercayai menjadi pembimbing atau guru dalam melakukan bimbingan praktek ritual ketarekatan. Bukan hal yang mudah bagi perempuan untuk menjadi seorang mursyid dalam kelompok spiritualitas tertentu, menjadi realita menarik untuk direnungkan. Bayangkan saja, sekian panjang deretan daftar nama mursyid (guru sufi, red) dalam sejarah sufisme adalah laki-laki. Jarang diantara mursyid (dah?) yang ditempati oleh kaum perempuan. Apakah karena terkesan lemah, apakah karena terkesan lembek atau terkesan tidak "kuat", lalu kaum perempuan jarang ditempatkan atau diposisikan sebagai mursyid?. Hal itu selayaknya menjadi perenungan bersama.

Sadar atau tidak, kita dituntut untuk mau menyadari persoalan yang pada dasarnya akan membodohkan jiwa-jiwa para spiritualis (sufi) dewasa ini. Realita tersebut secara kongkrit menambah persoalan baru dalam kajian spiritualitas. Persoalan yang tidak hanya menyulitkan ditumbuhkannya sistem keadilan di berbagai aspek kehidupan, namun juga persoalan yang akan menambah deretan panjang "dosa" laki-laki atas perlakuan selama ini kepada mahluk Tuhan yang beridentitas perempuan.

Kata spiritualitas, pada hakikatnya tidaklah diwakili atau mewakili satu golongan kelamin tertentu, misalkan laki-laki atau perempuan an sich. Akan tetapi, kata tersebut mempunyai kebesaran universalitas ruang lingkup, yaitu untuk laki-laki maupun perempuan. Ruang lingkup yang sangat luas dan tidak dibatasi sebatas ruang lingkup laki-laki semata. Dewasa ini, ruang lingkup universalitas spiritual itu terkesan disempitkan maknanya pada golongan laki-laki saja. Padahal, jika direnungkan kembali, perempuan juga memiliki hak berspiritualitas yang sama dengan laki-laki.

Begitu juga dalam hal kepemimpinan spiritualitas, diantara mursyidmursyid tasawuf yang berstatus perempuan jarang sekali bisa ditemukan. Permasalahannya adalah, apakah spiritualitas murni harus hadir dari hamba laki-laki, atau mengapa kapasitas kepemimpinan spiritualitas selama ini terkesan menjadi hak prerogratif laki-laki? Tidak bolehkah, kaum perempuan memimpin sebuah golongan spiritualitas tertentu misalkan golongan tasawuf Naqsabandiyah, atau tasawuf Qodiriyah? Persoalan tersebut, tentunya menjadi problem menarik untuk dituliskannya artikel ini. Paling tidak, semangat spirit ketuhanan kaum perempuan layak untuk diperhatikan minimal diakui diantara hamba-hamba Tuhan lainnya. Dengan kondisi dan situasi seperti ini, tentu hak prerogatif laki-laki dalam memimpin golongan spiritualitas sebuah 
komunitas tasawuf patut untuk diperbincangkan kembali, alih-alih untuk mempertimbangkan dan menguak rahasia spiritualitas perempuan.

\section{Gagalnya Produk Ajaran Spiritual, Tinjauan Budaya Islam}

Spiritualitas, sebagaimana terurai di atas tadi, tentunya membawa tumpukan problem baru atas "kepincangan" konsep spiritualitas itu sendiri. Spiritualitas yang seharusnya netral dari golongan status kelamin tertentu menjadi bias gender karena ada indikasi penindasan atas hak asasi perempuan. Perempuan selalu dikalahkan, perempuan selalu dinomor duakan, perempuan selalu dianggap lemah, ternyata bukan saja terjadi di sektor luar non-spiritual, namun juga terjadi pada wilayah spiritual. Hal itu tampak diantaranya pada sedikit atau jarangnya pemimpin tarekat yang berstatus perempuan. Bisa dirasakan, sekian panjang daftar mursyid (guru sufi, red) dalam sejarah sufisme adalah laki-laki. Nyaris sulit untuk mencari nama seorang mursyid dari kalangan perempuan, terkesan menjadi momok perbincangan pemerhati spiritual dewasa ini. Tentunya hal ini menjadi sebuah pertanyaan. Spiritualitas yang sangat ketat sekali hubungannya dengan Tuhan, menjadi ikut-ikutan .terkena bias budaya patriarkhisme

Kesucian spiritual yang diagungkan dan "disembah", menjadi terkesan hilang martabatnya ketika dalam praktiknya terkesan mengebiri dan memalingkan martabat kaum perempuan dalam proses mengisi kedudukan menjadi pemimpin dalam hal spiritual. Maka tak aneh jika kemudian jarang sekali pemimpin dalam sebuan tarekat tertentu diduduki oleh perempuan.

Pertanyaannya adalah, mengapa dalam bingkai kesucian spiritual, budaya patriarkhisme masih bercokol "eksis tersenyum" dan masih saja diimani dan diberi ruang?. Jawabannya mungkin terletak pada sejauh mana kedalaman ilmu seorang sufi itu sendiri. Masih ada rasa untuk minta dihormati, masih saja ada rasa untuk ingin menjadi pemimpin tertinggi dalam sektor keimanan kepada Tuhan, tentunya dapat menjadi memperlambat atau paling tidak menghambat proses penaikan kepada maqamat yang tertinggi. Apalagi sikap yang demikian pada akhirnya menjadikan kaum perempuan menjadi korban spiritual. Fenomena demikian, menjadikan tumpukan pertanyaan yang bisa ditujukan kepada praktik ini menjadi semakin menumpuk dan tentu saja pertanyaan yang sedikit terkesan negatif (jelek, red). Problem yang demikian ini, penting sekali untuk dicermati bagi pelaku ilmu ketarekatan, baik yang bersanad pada jalur Abu Bakar as Shidiq maupun Sayyidina Ali Bin Abi Thalib, Qadiriyyah dan Naqsabandiyah. 
Kedalaman ajaran spiritual, ajaran tarekat, atau ajaran kesufian, tidaklah mengenal atas apa yang disebut sebagai gender spirituil, ketimpangan sosial atas problem kelamin. Mungkin terdengar lucu, akan tetapi praktek lapangannya tidak bisa dipungkiri, para "pejabat" tarekat apapun namanya jarang sekali ditemukan mursyidnya berstatus perempuan, kalaupun ada bisa dihitung.

Apakah memang demikian, bahwa seorang pemimpin dalam sebuah golongan spiritual, tasawuf atau tarekat harus berstatus laki-laki? Apakah ada ajaran tasawuf yang mengatakan bahwa seorang mursyid harus laki-laki? atau apakah ini karena jarang disadari ada nabi yang berstatus perempuan atau apakah ini merupakan ajaran kedalaman sebuah tarekat?. Tentu saja pertanyaan tersebut bisa dikembangkan lebih luas lagi dalam kaitannya dengan mempertajam keilmuan Tuhan yang sangat netral, sangat suci, dan sangat adil. Meskipun demikian, problem konstruk sosial patriarki dicurigai masuk dalam wilayah kajian mengenai ketarekatan dimana banyak di dalamnya dikaji ilmu Tuhan.

Keadilan ilmu Tuhan pada dasarnya sangat halus (latif) dan bisa dinikmati oleh segala hambanya, baik laki-laki maupun perempuan. Tidak ada batas atau sekat yang menjadikan penghalang ilmu Tuhan untuk bisa dinikmati oleh hambanya. Selagi ilmu itu bermanfaat, bermaslahah, dan berguna bagi sesama mahluk untuk bisa menghambakan diri kepada Tuhan, tidak ada salahnya jika tapuk kepemimpinan ketarekatan diduduki oleh kaum perempuan.

Untuk menghambakan diri kepada Tuhan, tidak ada batas kelamin tertentu. Tuhan tidak milah-milih, dalam menerima penghambaan hamba kepada-Nya. Hanya yang berhati bersih, tulus dan ikhlas, dapat menjadi peluang untuk kemungkinan besar diterima di sisi-Nya. Bukan atau tidak harus berkelamin laki-laki an sich untuk bisa berdekat kepada Tuhan. Tuhan sangat sayang pada seluruh hamba-Nya, tidak dibatasi yang berkelamin laki-laki saja.

Kesayangan Tuhan melebihi simbol-simbol kelamin. Kelamin diciptakan pada dasarnya untuk menciptakan peradaban baru, dan bukan untuk menjadi penghalang beribadah kepada Tuhan. Firman Tuhan tidak ada yang secara eksplisit maupun implisit mengajarkan bahwa laki-lakilah yang mampu menjadi seorang hamba yang dekat kepada-Nya. Tuhan sebagai pencipta mahluknya, dikatakan dalam sebuah ayat al Quran, sangat dekat (fainni qarib) terhadap hambanya. Karena itu apa yang diminta kepada-Nya, tidak harus laki-laki atau perempuan, pasti dikabulkan oleh-Nya. Dengan demikian, dikabulkannya doa seorang hamba tidak tersekat oleh status kelamin.

Hal itu membuktikan bahwa spiritual pada hakikatnya bukan milik 
para kaum laki-laki saja. Dzunnun al Misri (796-861 M), tokoh sufi di Mesir, mendefinisikan konsep pendekatan diri kepada Allah yang disebutnya sebagai "ma'rifat" tidaklah didefinisikan atau diperuntukkan kepada laki-laki saja. Ma'rifat yang didefinisikan sebagai bentuk mengetahui Tuhan sedekat-dekatnya dengan hati sanubari tersebut tidak harus diperuntukkan bagi kaum laki-laki saja melainkan untuk perempuan juga (Gharbal, 1968: 847).

Dalam tasawuf, ma'rifat terkadang dipandang sebagai maqam dan terkadang sebagai hal keadaan. Ma'rifah yang haqiqi bukan pengetahuan tauhid yang dimiliki oleh semua orang mukmin dan bukan pula pengetahuan yang berdasarkan argumentasi dan penjelasan seperti yang dimiliki para filosuf, pujangga dan ulama', tetapi ma'rifat adalah pengetahuan tentang sifat-sifat kekuasaan Tuhan, yang dimiliki oleh para wali Allah yang memandang Tuhan dengan hati. Baik itu adalah hati hamba perempuan maupun laki-laki. Berbeda dengan konsep Abu Mughsy al Hussein bin Mansur al Hallaj (858-922 M), yang mengemukakan bahwa Tuhan memilih tubuh-tubuh manusia tertentu untuk mengambil tempat di dalamnya, setelah sifat-sifat kemanusiaan yang ada dalam tubuh itu dilenyapkan. Namun, dipilah-pilihnya bukan karena status laki-laki atau perempuan, melainkan sifat nasut (sifat kemanusian) yang ada pada hamba baik perempuan maupun laki-laki ketika telah dilenyapkan sifat kemanusiaannya.

Agar manusia, sang hamba, dapat bersatu dengan Tuhan, terlebih dahulu manusia harus menghilangkan sifat-sifat kemanusiaannya yaitu fana'. Kalau sifat kemanusiaan (nasut) itu telah hilang dan hanya tinggal sifat ketuhanan (lahut), maka disitulah Tuhan mulai dapat mengambil dalam dirinya, ketika itulah "roh Tuhan dan manusia" bersatu dalam tubuh manusia. Tentu dalam hal ini, sebagaimana dijelaskan di atas, tidak dibedakan apakah sang hamba berstatus laki-laki maupun perempuan. Akan tetapi, menjadi bermasalah ketika siklus rihlah seorang sufi, terlihat mengedepankan unsur kelaki-lakiannya dalam memperoleh derajat di hadapan Tuhan dengan mengorbankan eksistensi hamba Tuhan lainnya yang bernama perempuan. Sangat tragis bahkan mengerikan tatkala "derajat keimanan" hamba dalam upayanya menghambakan diri ke Tuhan harus saling sikut-menyikut, yang hanya akan bermuara pada persoalan dia (perempuan tidak suci) dan kita (laki-laki adalah suci).

Perempuan, merupakan bagian dari eksistensi komunitas basyari (insani). Kaitannya dengan kaum masculine, dia adalah sebagai ibu dari sufisufi termasyhur di dunia. Kehidupan masyarakat basyari, tidak akan ada tanpa keduanya. Keduanya memikul beban kebangkitan bersama sesuai dengan 
fitrah yang telah Allah SWT ciptakan dengan petunjuk bimbigan samawi.

Pada masa jahiliyyah, kondisi perempuan sangat terpojokkan hak-haknya dirampas, dan pandangan terhadapnya sangat mendiskreditkan, hingga datang Islam membebaskannya dari kezaliman jahiliyyah, mengembalikan dan memuliakannya sebagai insan, wanita, anak, ibu, dan anggota masyarakat. (Hassan, 1990: 41-50). Namun, meskipun demikian, tetap saja nuansa memarginalisasikan kaum perempuan terasa bahkan telah menjadi bias di berbagai produk ajaran Islam yang ada, termasuk di dalam ajaran tarekat (Engineer, 1999: 198-201).

Padahal perempuan juga berhak memperoleh pahala sebagaimana lakilakinya. Hal ini sesuai dengan firman Allah swt dalam al Quran, yaitu:

"Barang siap beramal saleh dari kalangan lelaki dan wanita sedang beriman, maka kami akan memberinya kehidupan yang baik dan mengganjarnya dengan pahala yang baik pula bagi apa yang mereka lakukan" (QS. al-Nahl: 97).

"Lalu Tuhan mereka menjawab permohonannya; sesungguhnya saya tidak akan menyianyiakan amal saleh dari kalian baik dari laki-laki maupun wanita, kalian adalah bagian dari yang lain" (QS. ali Imran: 195).

Perempuan sebagaimana djelaskan pada ayat di atas, merupakan bagian dari laki-laki, begitu juga sebaliknya. Artinya, keduanya saling melengkapi, bukan sebagai musuh atau dua jenis yang mesti dipertentangkan. Sebagaimana firman Tuhan:

"Laki-laki mukmin dan wanita mukminat sebagian sebagai pelindung bagi yang lain, mereka (saling) menyuruh berbuat kebajikan dan melarang perbuatan mungkar" (QS al-Taubah: 71).

Akhirnya, praktek ketarekatan yang demikian itu, di mana posisi perempuan dimarjinalkan, menjadikan disiplin ilmu ke spiritualan terkesan gagal. Produk ajaran yang masih setia atas unsur patriarkhisme yang berpijak dari konsep superioritas laki-laki atas perempuan telah menjadi isu sentral dalam wacana feminisme. Laki-laki menguasai anggota keluarga, harta dan sumber ekonomi serta posisi pengambil keputusan. Konstruksi budaya patriarkhi ini telah mapan dan berlangsung selama berabad-abad, tidak lagi dipandang sebagai ketimpangan, bahkan dipandang sebagai 'fakta alamiah.

Penulis yakini lambat laun akan ditinggalkan oleh jamaahnya. Karena, ajaran spiritual tidaklah mengenal status perempuan dan laki-laki. Ketika dalam dataran praktek ritual tarekat pada sebuah ajaran spiritual masih mengedepankan 
sikap patrimonial, tentu saja produk ajaran yang ada terancam gagal.

\section{Esensi Spiritualitas, Mengapa harus Didominasi Laki-Laki?}

Ditinjau dari perspektif gender, gerakan spiritual-sufisme sering dianggap bersikap "seksisme", dan terlalu berpihak pada patriarkhisme, yaitu ideologi kekuasaan laki-laki atas inferioritas perempuan. Tuduhan tersebut memang bukan tak beralasan. Selama ini, di kalangan kaum sufi berkembang suatu anggapan bahwa (kepemimpinan) spiritualitas adalah hak istimewa (prerogatif) laki-laki.

Sekian panjang daftar mursyid (guru sufi) dalam sejarah sufisme adalah laki-laki. Terasa kesulitan mencari nama seorang mursyid dari kalangan perempuan, menjadi data tambahan bahwa ternyata kaum perempuan tak dihiraukan dalam kultur spiritual. Mitos ini semakin diperkuat oleh satu pepatah Arab yang tumbuh di kalangan kaum sufi, bahwa "Thalib al-Mawla Mudzakar", yang berarti "pencari Tuhan adalah kaum laki-laki". Namun demikian, dalam sebuah penelitian, sejumlah nama wanita sufi dalam kurun waktu kurang lebih 10 abad, ditemukan tak kurang dari 120 nama wanita sufi.

Jika direnungkan dalam dataran esensi praktek spiritual, perempuan berhak memiliki peran sebagaimana peran laki-laki di masyarakat, terutama dalam praktek ritual. Karena peran ini, bukanlah milik kaum maskulin saja. Penjelasan al Quran tentang problematika perempuan sangat transparan, tetapi kaum muslim telah banyak memojokkan kaum perempuan pada masa-masa keterbelakangan dan kekalahan peradaban. Hak-haknya dirampas, rumahnya menjadi penjara, dan kebodohan terhadap permasalahan agama dan dunia merajalela disandarkan pada kaum perempuan.

Dari beberapa ayat al Quran, setidaknya memberi bukti, sufisme bukanlah hak monopoli manusia yang berjenis kelamin laki-laki saja. Tidak ada hak prerogatif bagi kaum laki-laki dalam wilayah spiritual. Fenomena ayat yang demikian, bukan saja membongkar mitos ketidak mampuan kaum perempuan untuk menjadi sufi dalam lintasan sejarah sufisme Islam, tapi juga membuktikan ada peluang bagi perempuan untuk dapat mencapai pengalaman spiritualitas hingga tingkat (maqamat) yang tertinggi, dan melampaui apa yang pernah dicapai oleh kaum pria.

Hal tersebut seperti diteladankan oleh perempuan sufi termasyhur dari Bashrah, yang hidup pada abad ke delapan, Rabi'ah al-Adawiyah. Ia (Rabi'ah) termasuk dalam golongan perempuan sufi yang mengungguli hampir semua tokoh sufi se-zamannya, baik dalam keutamaan sosial (mu'amalat) maupun 
pencapaiannya menuju Allah (ma'rifat) (Kalabadzi, 1985: 79). Karenanya, tak salah jika Farid al Din 'Aththar, salah satu tokoh besar dalam sufisme Islam, merasa perlu menyampaikan pujian secara khusus kepadanya. Hal itu seperti terungkap dalam salah satu kitabnya, Tadzkirah al-Awliya.

Tampilnya Rabi'ah al Adawiyah telah memberikan "pukulan keras" atas anggapan bahwa laki-laki memiliki hak prerogative dalam wilayah spiritual. Juga telah membantah bahwa perempuan termasuk mahluk Tuhan yang tak pantas menjadi pemegang kendali ajaran spiritual (baca; tasawuf). Dengan demikian, laki-laki dan perempuan tetap dalam tingkat kesederajatan, hanya saja keduanya memiliki fungsi atau peran yang berbeda, sesuai kodratnya (Smith, 1997: 3). Ajaran Islam, dalam memandang persoalan gender, lebih menganut "paham kesetaraan", yaitu setiap manusia baik pria maupun wanita- setara atau setingkat di hadapan Tuhan (Muhsin, 1994: 98). Hal itu seperti tecermin dalam beberapa dalil-dalil yang lain, baik al Quran maupun as Sunah, yang sering menyebut pria dan wanita secara bersamaan dan dalam posisi kesetaraan (Umma, 2002: 30).

Secara historis, perempuan sufi sudah menampakkan dirinya pada periode sangat awal, dan dalam perkembangan evolutif penghargaan terhadap kesucian diberikan sama tingginya antara kaum perempuan dan kaum laki-laki. Sejauh kajian mengenai "sahabat-sahabat Tuhan" ini dibicarakan, maka tidak akan ada perbedaan dalam jenis kelamin tersebut. Perkembangan sufisme dalam Islam memberikan kesempatan luas kepada kaum perempuan untuk mencapai gelar kesufian. Tujuan utama pencapain kaum sufi adalah untuk dapat menyatu dengan Yang Maha Suci, dan dalam pencarian tersebut mereka telah meninggalkan keindahan dan daya tarik gemerlapnya dunia dengan membakar gelora cintanya kepada Tuhan, secara terus menerus, guna mencapai tujuan paling akhir, yaitu menggapai pencerahan dalam kehidupan, bersama kegembiraan dan kegairahannya, dan perenungan kehidupan yang lebih tinggi, hingga akhirnya dapat mencapai ma'rifat dan menggapai Bayang-bayang Tuhan, di mana Sang Pencipta tersebut akan menjadi satu dengan yang dicintainya dan kekal bersama-Nya selamanya.

Meskipun demikian, ajaran sufi sampai sekarang, menurut penulis, belum sampai pada dataran upaya menguraikan atas adanya kesamaan posisi antara laki-laki dan perempuan. Masih saja banyak kaum tarekat yang tidak mau dipimpin oleh pemimpin perempuan. Tentu saja hal ini menambah deretan nama mursyid laki-laki di bidang tasawuf Islam semakin kuat. Kondisi yang demikian pada dasarnya merupakan bagian 
dari memarjinalkan pribadi kaum perempuan. Sampai kapanpun identitas perempuan tetap saja dimarjinalkan.

Munculnya diskriminasi yang merendahkan kaum perempuan beserta seluruh pengalaman dan pemikirannya sebagaimana terurai tersebut, jika dirunut kebelakang, berakar sekitar 10.000 tahun lalu, sejak millenium ke empat sebelum Masehi. Pada saat itu laki-laki mulai membangun apa yang dinamakan patriark-supremasi laki-laki. Dalam karyanya "A Discourse on Political Economy" (1755), filsuf Jean Jacques Rousseau secara konsisten memandang perempuan sebagai makhluk inferior dan tersubordinasi. Tujuan hidup mereka hanya untuk melayani laki-laki. Karena itu, mereka tidak mungkin atau tidak dapat menjadi pemimpin. Dalam mistik Islam atau dunia sufisme, perbedaan gender pada dasarnya bukan merupakan faktor utama yang menentukan dalam pencapaian spiritualitas. Bukankah sejarah telah membuktikan, sebagaimana diuraikan beberapa peneliti sufisme kontemporer, tak sedikit wanita-wanita sufi yang mampu mencapai kedudukan (maqamat) yang tinggi dalam pencapaian spiritualitas Bahkan, dalam hal tertentu, wanita justru mendapat keutamaan dalam Islam (Al Hamdani, 1979: 54-61).

\section{Simpulan}

Dari pemaparan di atas, terdapat beberapa kesimpulan yang menarik untuk diperhatikan; Pertama, meskipun pada dunia sufistik dikenal tokoh perempuan seperti halnya Rabi'ah al Adawiyah, namun tetap saja para pelaku di berbagai kelompok budaya tarekat, tidak rela jika ketua atau mursyidnya dipegang oleh mereka yang berstatus perempuan. Kedua, sekalipun ada beberapa ayat al Quran mengindikasikan bahwa mahluk yang namanya lakilaki dan perempuan adalah setara dihadapan Allah, tetap saja di dalam upaya mengembangkan keadilan spiritual berbasis jender, tidak bisa dipeluangkan kepada perempuan sebagai pemimpin tarekat. Ketiga, hak prerogatif laki-laki dalam disiplin ketarekatan khususnya untuk menjadi mursyid tasawuf untuk ukuran peradaban Islam sekarang- tidak bisa dialihkan kepada mereka yang berstatus perempuan, kecuali kultur budaya patriarkhi dicabut dari akar renung jiwa para sufi. Termasuk silsilah panjang yang kadang bahkan jarang sekali ditemukan nama-nama perempuan. 


\section{Daftar Pustaka}

Ahmed, Leyla. 1993. Women and Gender in Islam; Historical Roots of a Modern Debate. Kairo: The AUC Press.

Al Hamdani, SA. 1979. Al Tasawuf al Islamu Baina al Din wa al Falsaf. Kairo: Dar al Nahdhah al Arabiyah.

Ali, Amer. 1978. Api Islam: Sejarah Evolusi dan Cita-Cita Islam dengan Riwayat Hidup Muhammad. Jakarta: Bulan Bintang.

Arberry, A.J. 1985. Sufism; An Account of The Mystics of Islam. Terjemahan oleh Bambang Herawan. Pasang Surut Aliran Tasawuf. Bandung: Mizan.

Engineer, Asghar Ali. 1999. Islam dan Teologi Pembebasan. Terjemahan oleh Agung Prihantoro. Yogyakarta: Pustaka Pelajar.

Gharbal, Muhammad Syarif. 1968. Al Mausu'ah al Arabiyah al Islamiyah. Kairo: Dar al Qalam.

Hassan, Riffat. 1990. Teologi Perempuan dalam Tradisi Islam; Sejajar dihadapan Allah?. Jurnal Ulumul Qur'an, No. 4.

Kalabadzi, Abu Bakar M. 1985. Al Ta'aruf Li Madzhab al Tashawuf. Terjemahan oleh Nasir Yusuf. Ajaran-Ajaran Sufi. Bandung: Pustaka.

Muhsin, Amina Wadud. 1994. Wanita di dalam al Quran. Terjemahan oleh Yaziar Radianti. Bandung: Pustaka.

Quzwan, M. Chatib. 1985. Mengenal Allah. Jakarta: Bulan Bintang.

Smith, Margaret. 1997. Rabi'ah; Pergulatan Spiritual Perempuan. Terjemahan oleh Jamilah Baraja. Surabaya: Risalah Gusti.

Umma, Mohammad Fauzi. 2002. Bias Jender dalam Pemahaman Islam. Ed; Sri Suhardjati Sukri. Yogyakarta: Gama Media. 